\title{
Experiencias y proyecciones del patrimonio industrial chileno
}

\author{
Mauricio Lorca
}

El carácter patrimonial de las manifestaciones asociadas a las actividades industriales se sitúa en los países desarrollados a partir de la segunda mitad del siglo XX. Tal fenómeno respondió a la presión que comenzaron a sufrir los espacios y las maquinarias industriales producto de las modificaciones y las reconversiones técnicas que desde ese momento comenzaron a sucederse en el mundo. En efecto, a finales de la década de 1960 se identifica, alrededor del conjunto minero inglés de lronbridge, la primera iniciativa de activación, puesta en valor y conservación de restos industriales en el mundo (Cerdà, 2008, p. 27).

A partir de ese momento se detectan una serie de acciones que, principalmente lideradas por administraciones locales y estatales, reutilizan bienes industriales en el diseño y la ejecución de políticas de ordenación y planificación de antiguos territorios industriales y en estrategias orientadas a sortear las tensiones económicas y sociales asociadas a escenarios posindustriales. A esas acciones se fueron sumando gestiones emprendidas por el mundo asociativo que -en buena medida motivado por los principios formulados por la nueva museología francesa de la década de 1970- se lanzó a la elaboración de inventarios, registros locales y la puesta en marcha de espacios museográficos que dan cuenta del aprecio social que poseen algunos de estos restos para las comunidades vecinas. De esta forma, los bienes industriales patrimoniales poco a poco se fueron transformando en estructuradores de significado e identidad en muchos territorios'.

En Chile la toma de conciencia del valor patrimonial de los bienes legados por la industria es un proceso socialmente más tardío que en los países desarrollados. En efecto, si bien en la década de 1970 se identifican una serie de activaciones que centran la valoración de estos bienes principalmente en su importancia histórica asociándolos a procesos sociales y económicos relevantes para el país, hubo que esperar hasta la década de 1990 para que este sector del patrimonio comenzara a definirse como una tipología dentro del campo patrimonial nacional, y la llegada del siglo XXI para que esa tendencia se consolidara gracias a la adhesión a las dinámicas de activación de bienes industriales de actores pertenecientes a la sociedad civil y al ámbito privado.

Este artículo expone la trayectoria que ha tenido el patrimonio industrial chileno y las perspectivas que se observan para este sector. El trabajo se fundamenta en algunas entrevistas realizadas durante

* Cómo citar este artículo: Lorca, M. (2017). Experiencias y proyecciones del patrimonio industrial chileno. Apuntes, 30(1), 54-69. https://doi.org/10.11144/Javeriana.apc30-1.eppi 


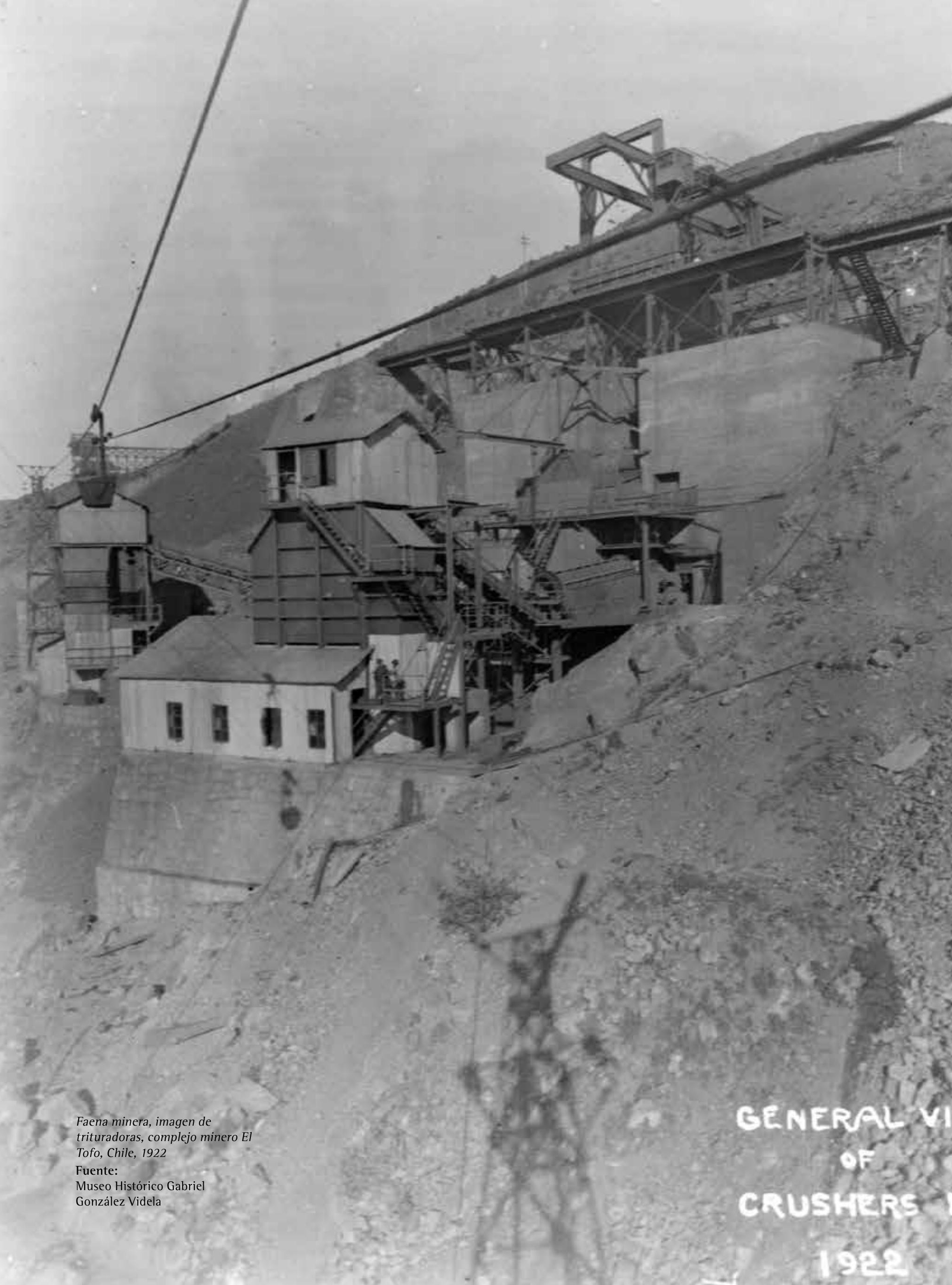




\title{
Experiencias y proyecciones del patrimonio industrial chileno
}

\author{
Experiences and Projections of Chilean Industrial Heritage \\ Experiências e Projeções do Patrimônio Industrial Chileno
}

\section{Mauricio Lorca}

maurolorca@gmail.com - Universidad Autónoma de Chile. Av. Pedro de Valdivia 425, Providencia, Santiago de Chile. Se adiciona el siguiente texto: Universidad de Atacama. Facultades Ciencias de la Salud, Jurídicas y Sociales

Antropólogo de la Universidad de Chile; máster en Historia mención Etnohistoria de la Universidad de Chile; DEA en Estudios del desarrollo de la Universidad de Ginebra; doctor en Gestión de la Cultura y el Patrimonio de la Universidad de Barcelona. Ha desarrollado diferentes consultorías vinculadas a investigación y gestión en temáticas relacionadas a la identidad, la cultura local, los pueblos originarios y el patrimonio. Asimismo, ha participado en distintos congresos, cursos y seminarios en las mismas materias.

\section{Resumen}

En Chile, la toma de conciencia del valor patrimonial de los bienes legados por la industria es un proceso social más tardío que en los países desarrollados. Pese a que desde el año 1952 numerosos decretos leyes han entregado la condición de monumento nacional al centenar de elementos que conforman esta tipología, hubo que esperar hasta la década de 1990 para que el sector industrial se consolidara dentro del campo patrimonial chileno. Este artículo reflexiona sobre la trayectoria y las perspectivas del patrimonio industrial del país, identifica los períodos que ha atravesado, su distribución geográfica, los sectores productivos representados y las proyecciones que se estima posee.

Palabras clave: Chile; patrimonialización; patrimonio industrial; refuncionalización; valoración social

Abstract

In Chile, the awareness of the heritage value of the goods handed down by the industry is a slower social process than in developed countries. Despite the fact that since 1952, numerous decrees and laws have handed over the status of national monument to the hundreds of elements that comprise this typology, it was not until the 1990s that the industrial sector was consolidated within the Chilean heritage field. This article reflects on the trajectory and perspectives of the industrial heritage of the country, identifying the periods it has gone through, its geographical distribution, the production sectors represented, and the projections it is estimated to have.

Artículo de investigación

Recepción: 19 de junio de 2016

Aceptación: 20 de noviembre de 2016

Disponible en línea: 10 de diciembre de 2017
Keywords: Chile; granting heritage status; industrial heritage; repurposing; social valuation

\section{Resumo}

No Chile, a tomada de consciência do valor patrimonial dos bens legados pela indústria é um processo social mais tardio que nos países desenvolvidos. Apesar de numerosos decretos-leis terem entregado o status de monumento nacional para os cem elementos que conformam tal tipologia desde o ano 1952, não foi até a década de 1990 que o sector industrial se consolidou no campo patrimonial chileno. Este artigo reflete sobre a trajetória e as perspectivas do patrimônio industrial do país, identificando os períodos que já viveu, sua distribuição geográfica, os sectores produtivos representados e as projeções que se estima possuir.

Palavras-chave: Chile; patrimonialização; patrimonio industrial; refuncionalização; valoração social

doi:10.11144/Javeriana.apc30-1.eppi 
los meses de agosto y septiembre de 2015 y en la revisión de los decretos leyes que, entre 1952 y 2015, confirieron la condición de monumento nacional en la categoría histórica o como zona típica o pintoresca a los más de 106 bienes que conforman el universo patrimonial industrial chileno $^{2}$. Esto permitió identificar la distribución del patrimonio industrial en el país, los sectores productivos representados y la evolución que han tenido las declaraciones patrimoniales de bienes industriales desde que en 1952 fuera declarado monumento nacional el primer elemento industrial del país.

\section{Una nueva categoría patrimonial: el sector industrial}

Uno de los más recientes ámbitos de estudio y tutela patrimonial es el industrial pero, a pesar de su enorme amplitud, dada la cantidad y la diversidad de áreas de la producción que comprende, en términos sociales no es muy valorado. Seguramente porque, como plantea Casanelles (2007), somos la primera generación que considera como patrimoniales objetos que han sido utilizados por nosotros mismos. Por ende, no es raro considerar a los bienes industriales como no dignos de interés ya sea porque cronológicamente son recientes, porque han tenido finalidades utilitarias o porque al estar relacionados al mundo del trabajo se asocian a rutinas, sufrimientos y privaciones. Pero también debido a que, sin duda, las administraciones responsables siguen centrando sus acciones en conjuntos patrimoniales más tradicionales y consolidados y porque, dada su extraordinaria complejidad, el patrimonio industrial requiere de investigaciones novedosas y una gestión específica (Fernández-Baca, 2007).

Efectivamente, la inclusión de lo industrial dentro del campo patrimonial ha significado una serie de replanteamientos respecto a los criterios de apreciación, protección y preservación tradicionales -como la belleza, la monumentalidad y la antigüedad-que no son aplicables a esta clase de bienes. Esto ha inaugurado una nueva forma de entender la antigüedad pues, dada la rapidez con que actualmente acontecen los cambios tecnológicos, objetos hasta hace poco funcionales pasan rápidamente a la obsolescencia. Asimismo, porque los elementos industriales se han constituido en testimonios con valor documental y antropológico ya que, como parte del mundo industrial, permiten el estudio y la comprensión de esa sociedad específica (Casanelles, 2007; Instituto del Patrimonio Cultural de España, 2011). Igualmente, como han hecho ver autores como Marrodán (2007) y Aguilar (2007), debe también destacarse la tendencia a valorar los restos físicos dejados por la era industrial desde una perspectiva puramente estética.

El interés por la salvaguarda del legado industrial se institucionalizó en 1978 con la creación del Comité Internacional para la Conservación del Patrimonio Industrial (Ticcih) como la organización encargada de la protección, la promoción y la interpretación de ese patrimonio en el ámbito mundial. Luego, en 1985, el sector industrial pasó oficialmente a formar parte de la discusión patrimonial con la convocatoria al primer encuentro internacional temático: el coloquio, celebrado en Lyon, titulado ¿Qué políticas para el patrimonio industrial?

En ese espacio de discusión, por primera vez se reconoció que lo industrial es parte del campo patrimonial pues "la cultura industrial es un elemento constitutivo y merece la misma atención que el resto de sus aspectos [ya que son] el producto de procesos tecnológicos y habilidades profesionales que son testimonios de una civilización y portadores de un hecho cultural” (Consejo de Europa, 1987, p. 147). En otras palabras, el patrimonio industrial posee implicancias sociales y culturales asociadas al mundo del trabajo pero también a la vida cotidiana.

A partir de entonces, los esfuerzos por proteger y conservar el patrimonio industrial se han sustentado en que representa una "memoria histórica que se manifiesta diferencialmente según la época, la fase de desarrollo, los sectores de actividad y las áreas geoculturales en que se llevó a cabo el proceso de la industrialización" (Instituto del Patrimonio Cultural de España, 2011 , p. 3). El valor de esta definición radica en que declara objeto de estudio tanto los bienes materiales como los intangibles, incluidos también los aspectos paisajísticos relacionados a los componentes industriales.

Efectivamente, una de las características constitutivas de los bienes que conforman esta tipología patrimonial es la espacial: el patrimonio industrial está profundamente ligado al lugar en que se emplaza. Esto quiere decir que los elementos industriales deben ser interpretados no de forma aislada, sino incorporándolos al territorio
2 Parte de la información utilizada para la elaboración de este artículo pertenece a la tesis doctoral del autor: "Dinámicas de patrimonialización del legado mineroindustrial en el Norte Chico. Patrimonio y sociedad en Chile contemporáneo" del programa en Gestión de la Cultura y el Patrimonio de la Universidad de Barcelona. 
que pertenecen (Bergeron y Dorel-Ferré, 1996; Benito del Pozo, 2002; Quivik, 2000; Pardo, 2008; etc.). Es decir, en palabras de Therrien (2008, p. 49), "los bienes y expresiones culturales asumen un carácter relacional y no aislado, como referentes entre sí y con el entorno, lo que les otorga contexto y significado".

De este modo, emerge un "patrimonio territorial” cuyo aspecto más destacable es que "incorpora una dimensión evolutiva y transformadora que permite reconocer los atributos edificados y no edificados que existen en el territorio y que se corresponden con una cultura o con una determinada forma de organización social o de quehacer humano" (Castillo y Tremiño, 1998, citados en Cañizares, 2005, p. 24). Se conforma así un binomio patrimonio industrial-patrimonio territorial que identifica y destaca la pertenencia de un grupo a un espacio geográfico y cultural y revaloriza el territorio y los elementos presentes en su interior, dándoles la oportunidad de constituirse en recursos que trascienden el campo cultural mediante proyectos que aspiran a dinamizar espacios económicamente decadentes (Mata, 2008; Sabaté y Benito del Pozo, 2010; Feria, 2010; Pardo, 2011; Benito del Pozo, 2012; entre otros).

La definición más actualizada del patrimonio industrial la entrega la Carta de Nizhny-Tagil, que lo entiende como "los restos de la cultura industrial que poseen un valor histórico, tecnológico, social, arquitectónico o científico. Estos restos consisten en edificios y maquinaria, talleres, molinos y fábricas, minas y sitios para procesar y refinar, almacenes y depósitos, lugares donde se genera, se transmite y se usa energía, medios de transporte y toda su infraestructura, así como los sitios donde se desarrollan las actividades sociales relacionadas con la industria, tales como la vivienda, el culto religioso o la educación" (Comité Internacional para la Conservación del Patrimonio Industrial, 2003).

Actualmente se estima que las manifestaciones asociadas al patrimonio industrial se sitúan temporalmente entre mediados del siglo XVIll y el último tercio del siglo XX y son "el resultado de una determinada relación social, la capitalista, y con un concreto sistema tecnológico, la mecanización" (Instituto del Patrimonio Cultural de España, 2011, p. 7). Esto excluye de esta categoría a los elementos pertenecientes a las épocas pre y proto industriales, pues esas manifestaciones están comprendidas en otras clasificaciones patrimoniales.
Esta delimitación temporal incluye dentro del patrimonio industrial a una amplia variedad de sectores relacionados con la producción, entre ellos: la minería y las actividades extractivas, la producción de energía (gas, electricidad, petróleo), la industria textil (lavaderos de lanas, fábricas y colonias textiles), la industria del papel y las artes gráficas, la industria agroalimentaria (silos, destilerías, harineras, chocolates, dulces), la industria naval (embarcaciones, diques, astilleros), del juguete, del transporte (ferrocarriles, automóviles, embarcaciones, aeronaves), las comunicaciones (correos, teléfonos, telégrafos), las vías de comunicación, etc.

Ahora bien, dentro de los principales desafíos que enfrentan los bienes industriales de características patrimoniales está la escasa protección legal que poseen debido al enorme número de elementos que comprende el patrimonio industrial. Además, la perspectiva territorial que este involucra plantea serias dificultades para protegerle, ya que "cuando las manifestaciones del patrimonio industrial definen paisajes o espacios, su protección no puede venir de la mano, exclusivamente, de las técnicas reguladas en la legislación sectorial, sino que requiere una integración y coordinación con los mecanismos de la ordenación territorial y con las políticas de desarrollo económico y social" (Alonso, 2002, p. 113).

Otro de los retos que enfrenta esta categoría patrimonial es la pugna existente entre intereses económicos e intereses culturales. Dado que la mayoría de los bienes inmuebles y muebles pertenecen a privados y representan activos y herramientas de trabajo que pueden ser demolidas, desechadas, vendidas o destinadas a nuevos usos en el momento en que sus propietarios estimen que su vida útil cesó (Tajter, 2008). A esto se añade el peligro de expolio al que permanentemente están expuestos los bienes muebles, la infraestructura y los archivos industriales cuando una fábrica, una mina o una empresa se cierran y/o abandonan. Del mismo modo, tampoco es extraño que las entidades inmateriales relacionadas al patrimonio industrial se vean fuertemente amenazadas de desaparición cuando los oficios y, en general, los conocimientos y las formas de organización que le están asociadas quedan en desuso y los sujetos depositarios de esos conocimientos desaparecen sin dejar testimonio.

No obstante, así como el patrimonio industrial presenta amenazas y debilidades, tam- 
bién posee fortalezas, ya que no pocas veces su puesta en valor es sinónimo de potencialidades en escenarios posindustriales y/o de cierre de faenas mineras que conllevan tensiones sociales asociadas a la pérdida de empleos y la caída en el nivel de renta relacionadas a procesos de desindustrialización. De ahí que parte importante de las contribuciones del patrimonio industrial actualmente se centren, primero, en su reconversión en recurso de dinamización en áreas que han visto declinar sus economías; segundo, como criterios que se deben considerar en la ordenación y la planificación territorial y, tercero, como activos sobre los cuales construir procesos orientados a la singularización y el mantenimiento de antiguos territorios industriales, es decir, como elementos estructurados de memorias e identidades específicas.

\section{El patrimonio industrial chileno}

La mayor parte de las áreas productivas que conforman el patrimonio industrial chileno pertenece a sectores extractivos, siendo excepcionales los casos que corresponden a procesos de manufactura. Es decir, la vida útil de la mayoría de los bienes que componen el patrimonio industrial del país se acotó a la existencia de materias primas y la vigencia de los sistemas extractivos de los que formaban parte. Esto, sumado a las marcadas características sísmicas del país, explica por qué el estado de conservación de muchos de esos bienes corresponde a ruinas.

El período en que se desarrolló la vida útil de la mayoría de esos elementos pertenecen a la denominada Segunda Revolución Industrial, etapa que más o menos abarca desde 1870 y el comienzo de la Primera Guerra Mundial en 1914. En otras palabras, según Cormín (2005), se insertan dentro de los cambios sociales y económicos que se produjeron como consecuencia de las transformaciones asociadas a las innovaciones tecnológicas relacionadas con nuevas fuentes de energía (gas, petróleo y electricidad); la aparición de nuevos materiales y sistemas de transporte y comunicación; cambios organizativos en las empresas, el mercado, la forma de organización del trabajo y el consumo; el reforzamiento del rol del Estado en el ámbito económico y, gracias a la progresiva internacionalización de la economía, el nacimiento de la primera globalización.

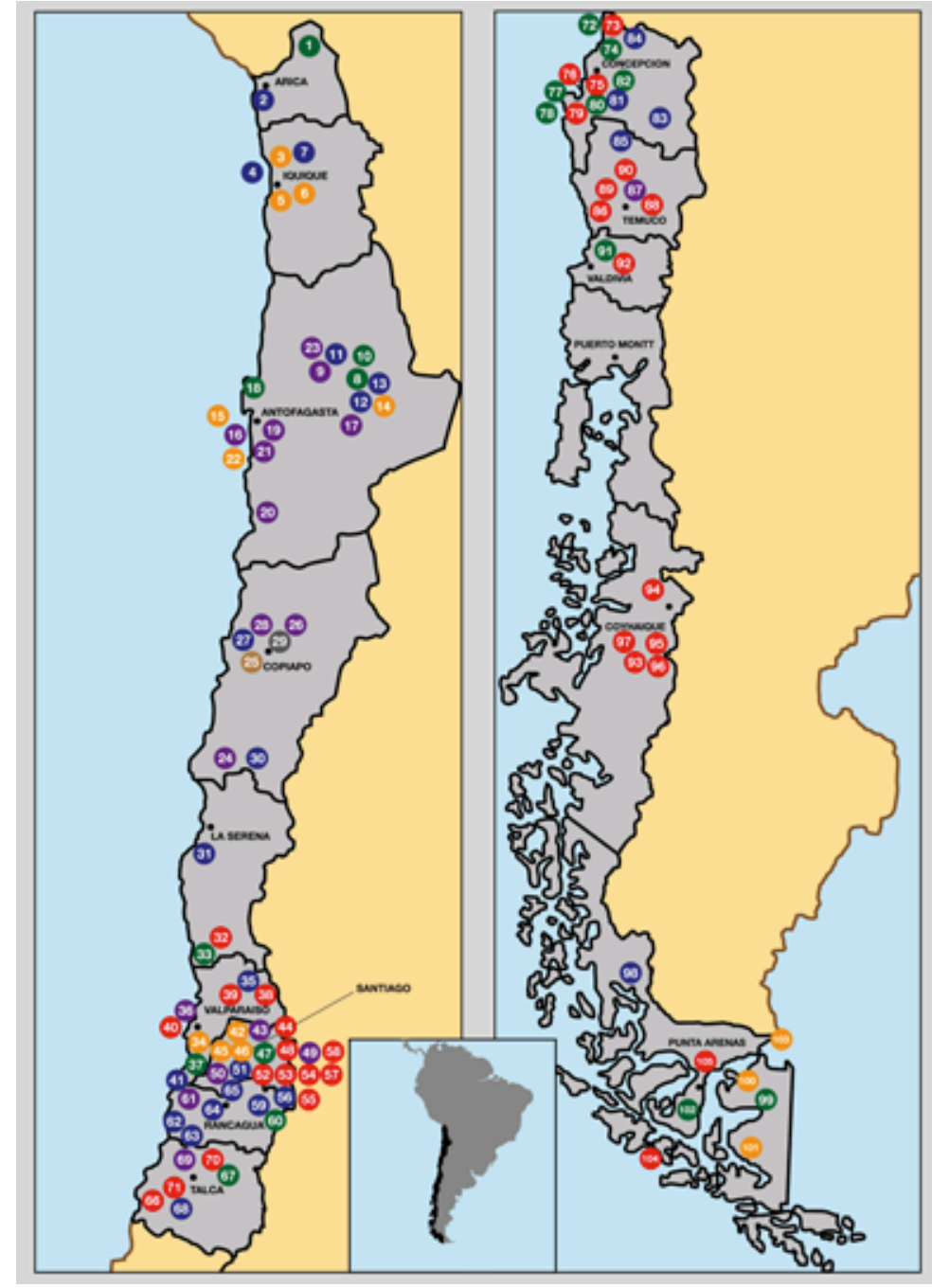

Las figuras 1a, 1b y 1c permiten apreciar los sectores de la producción que comprenden el patrimonio industrial nacional, sobresalen las áreas metalúrgica (antiguas fundiciones de cobre y plata, chimeneas) y minera (antiguas oficinas salitreras, antiguos campamentos cupriferos, cabrías, minas de carbón, complejos industriales, pozos y campamentos petroleros, etc.); las industrias alimenticia (edificaciones que fueron haciendas agrícolas, frigoríficos ganaderos, fábricas de cerveza, bodegas vitivinícolas, etc.) y textil y forestal (fábricas, aserraderos, etc.); el ámbito vial, de las obras públicas y los transportes (viaductos, puentes, túneles, ascensores, funiculares, etc.); la esfera marítima y portuaria (molos, muelles, embarcaciones, antiguas balleneras, faros, etc.); los sectores hídrico (tranques, plantas hidroeléctricas y acueductos) y ferroviario (estaciones, edificios, recintos, ramales, maestranzas, etc.) y las piezas rodantes, aeronaves y trolebuses (locomotoras, coches, locomóviles, aviones y trolebuses).
Figura 1a:

Ubicación del patrimonio industrial nacional y

listado de bienes que lo conforman indicando década de declaratoria (ver las figuras $1 b$ y $1 \mathrm{c}$ ) Fuente:

Elaboración propia con base en decretos leyes dictados entre 1952 y 2015 


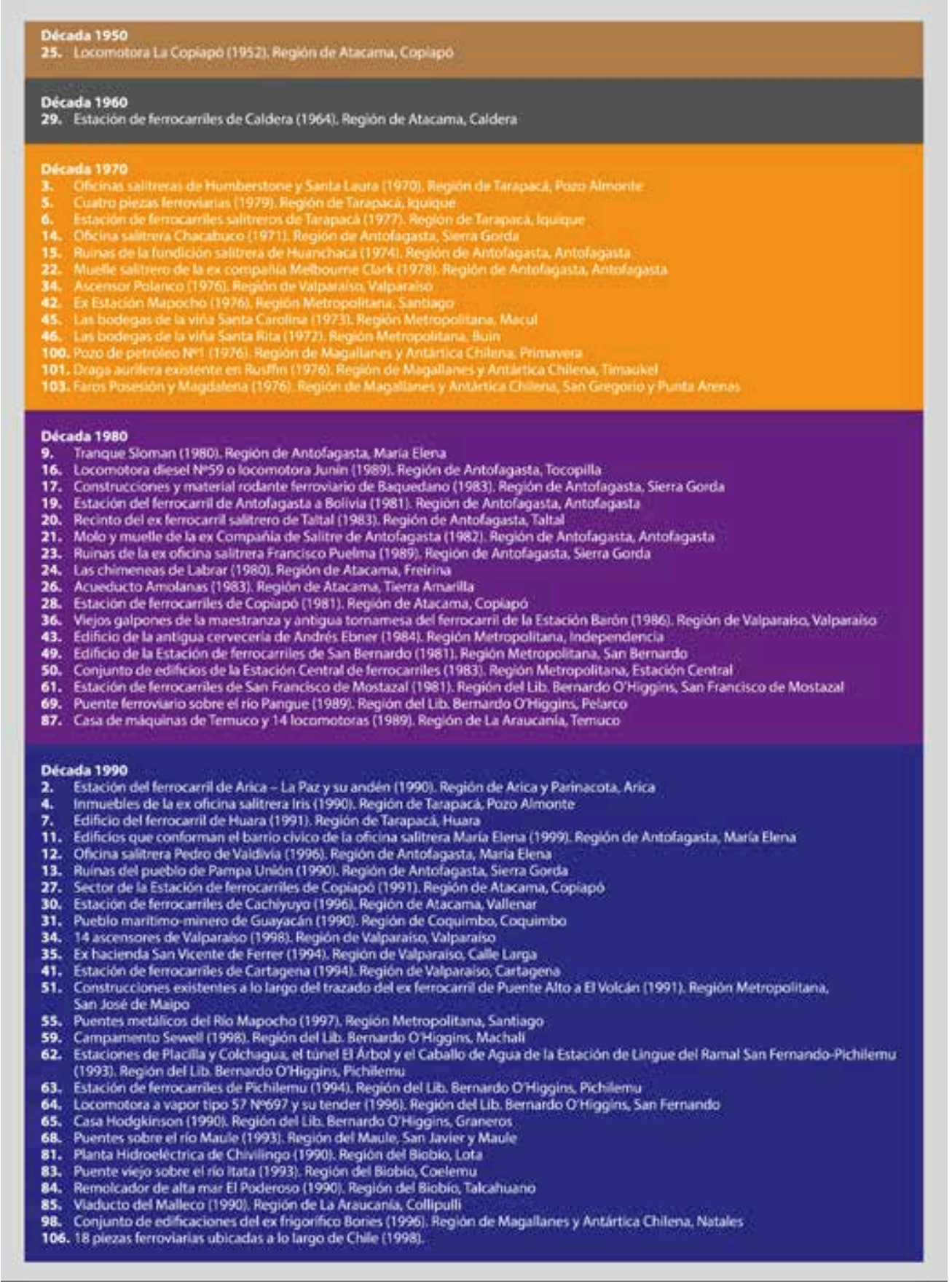

Figura 1b:

Inventario de infraestructura

registrada en los inventarios de patrimonio industrial en la segunda mitad del siglo XX

Fuente:

Elaboración propia con base en decretos leyes dictados entre 1952 y 2015

Como muestra el gráfico 1 (Figura 2), entre las áreas productivas que componen el universo patrimonial industrial nacional, claramente el ferroviario es el sector predominante con un $28 \%$. Esto sumado a que parte importante de estos bienes corresponden a locomotoras a vapor, eléctricas y diesel, coches y barrenieves y que a ellos es posible sumar los túneles, los puentes y los viaductos que fueron parte de la red ferroviaria, arroja como resultado que al menos $1 / 3$ del patrimonio industrial nacional está compuesto por bienes asociados al ferrocarril. El siguiente sector productivo mejor representado del patrimonio industrial nacional es, con un 24\%, el minero. Estos bienes mayoritariamente conciernen el auge salitrero y elementos relacionados con la extracción de carbón en el golfo de Arauco, especialmente los existentes en la ciudad de Lota. Esta cifra se ve levemente incrementada si se añade, dada su intrínseca relación, el sector "metalurgia" (3\%).

Por su parte, el gráfico 2 (Figura 3) permite distinguir en qué lugares del país se concentran los bienes industriales nacionales y muestra que las declaraciones realizadas se agrupan de forma 


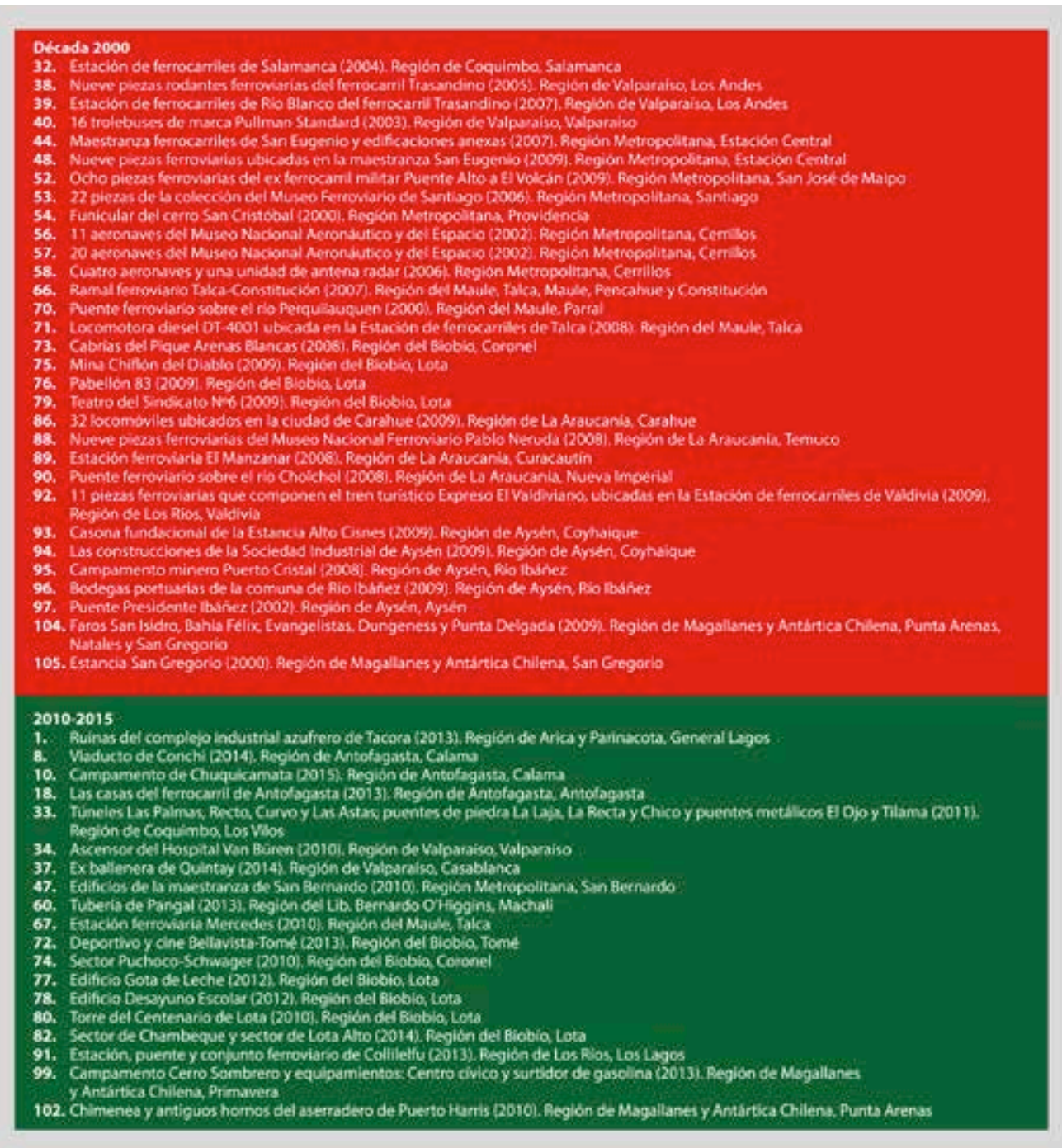

notoria en algunas regiones en detrimento de otras. Es el caso de la Región Metropolitana, con 17 elementos pertenecientes a distintos sectores productivos, y la Región de Antofagasta, con 16 elementos directa o indirectamente asociados a la explotación salitrera. Es decir, ambas regiones concentran el 31\% del patrimonio industrial nacional, les sigue la Región del Biobío que, con 13 bienes mayoritariamente relacionados con la minería carbonífera, posee el 12\% del universo patrimonial industrial del país, mientras que en sus antípodas se sitúa la Región de Los Lagos, que no posee bienes industriales reconocidos legalmente como patrimonio.

\section{La extensión del patrimonio industrial chileno}

Ahora bien, si se entiende al patrimonio como una representación dinámica que vincula el
Figura 1c:

Inventario de

infraestructura registrada en los inventarios de patrimonio industrial del año 2000 al 2015

Fuente:

Elaboración propia con base en decretos leyes dictados entre 1952 y 2015

Figura 2:

Prafico 1: Porcentaje por sector productivo representado dentro del patrimonio industrial nacional Fuente:

Elaboración propia a partir de las figuras 1

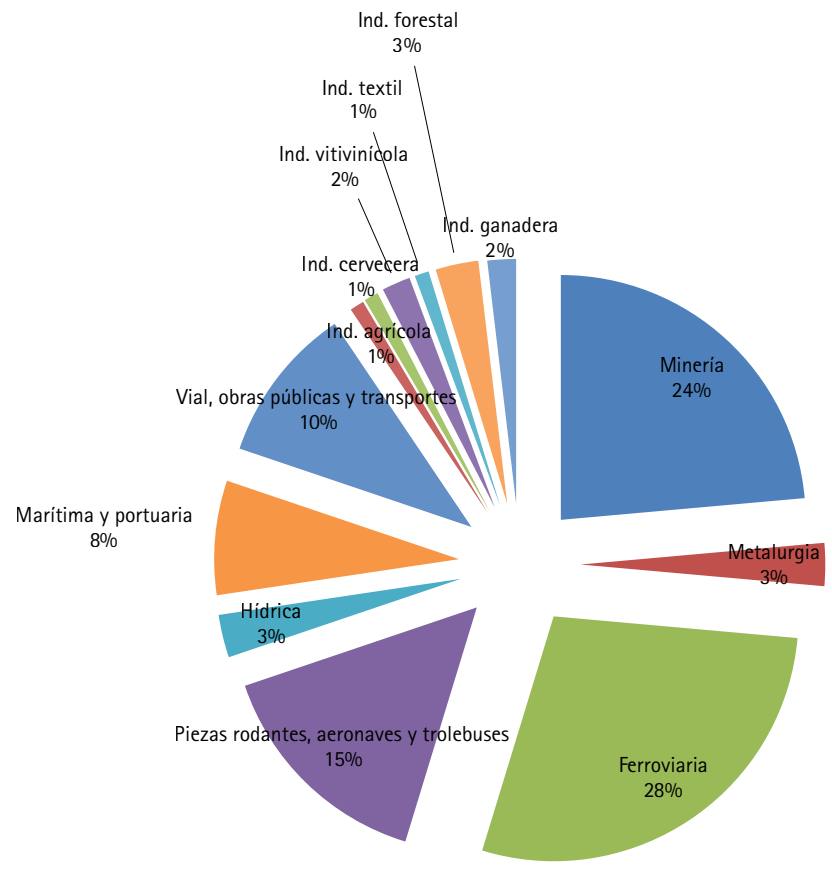




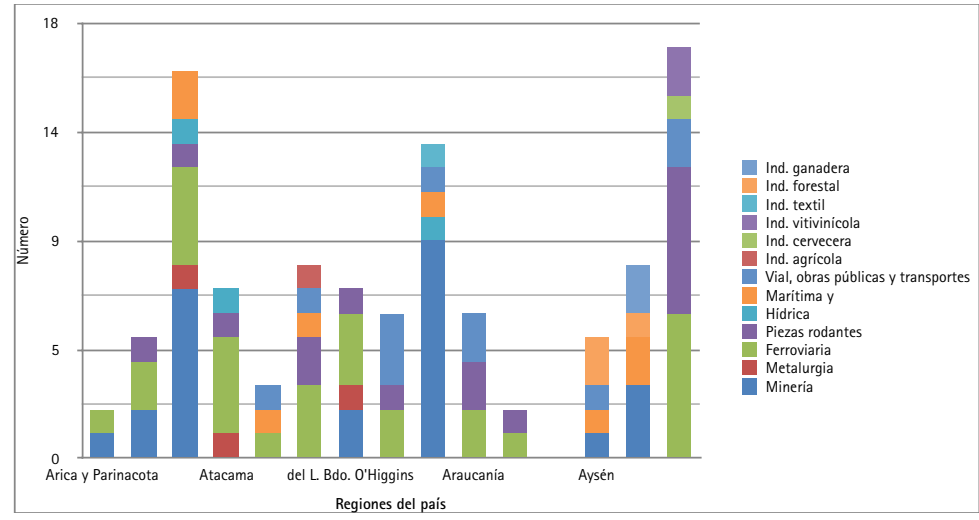

Figura 3:

Gráfico 2: Distribución del patrimonio nacional según región

Fuente:

Elaboración propia a partir de las figuras 1

Figura 4:

Gráfico 3: Número de declaraciones patrimoniales de bienes industriales desde 1952 a la fecha Fuente:

Elaboración propia a partir de las figuras 1 presente con el pasado para darles continuidad cultural según las necesidades, los intereses y los enfoques de cada época, se obtiene que la patrimonialización, como proceso de aumento de la carga simbólica, es la que permite que un bien cultural sea distinguido como patrimonio. Vale decir, el patrimonio debe entenderse no tanto como un valor en sí mismo sino como el resultado de un proceso de producción a partir de problemáticas contemporáneas. En otras palabras, es mediante la articulación de un discurso que comprende la identificación, la selección, el ordenamiento, el estudio, la interpretación, la certificación científica y la exhibición sobre el que debe centrarse el análisis sobre la emergencia de un elemento patrimonial (Prats, 1997; Kirshenblatt-Gimblett, 2001; Davallon, 2006; François, Hirczak y Senil, 2006). patrimonial de los bienes legados por la industria es un proceso que, aunque es posible situar sus inicios en la década de 1970, en términos sociales es más tardío que el europeo o el estadounidense. Efectivamente, salvo las declaraciones como monumento nacional histórico de la locomotora La Copiapó en 1952 y de la estación de trenes de Caldera en 1964, el reconocimiento legal de elementos industriales en el país se inicia en esa década para, desde ese momento, incrementarse
En Chile, la toma de conciencia del valor sostenidamente. En cuanto a la participación de la sociedad civil en los procesos de activación de bienes industriales, aunque algunos grupos comenzaron tímidamente a incorporarse a los procesos de patrimonialización durante la década de 1980, fue solo a partir de este siglo cuando se unen definitivamente a las dinámicas de activación de bienes industriales. Asimismo, el sector privado también se suma durante este siglo a los actores sociales que lideran este tipo de acciones por medio de la ejecución de proyectos de recuperación y refuncionalización de espacios industriales en estado de abandono.

En efecto, como muestra el gráfico 3 (Figura 4), el reconocimiento patrimonial de bienes industriales se ha incrementado progresivamente desde 1952, ha aumentado en número y se ha extendido por todo el territorio nacional. Si bien se detecta una declaración patrimonial durante la década de 1950 y otra en la de 1960, es a partir de los años setenta que la declaración de bienes industriales se acrecienta de forma constante: 13 de los bienes que conforman el patrimonio industrial del país a fecha de hoy fueron declarados durante esa década (12\%); 17 son reconocidos durante los años 1980 (16\%); 26 en la década de 1990 (24\%); 31 recibieron la categoría patrimonial durante la primera década de este siglo (29\%) para, entre los años 2010 y 2015, ser declarados como patrimonio 19 de los bienes que componen el patrimonio industrial nacional (17\%).

Ahora bien, si se centra la atención en la progresiva incorporación de actores sociales a los procesos de activación patrimonial de bienes industriales, los fundamentos en que se basa el reconocimiento de esos elementos como monumentos nacionales y las funciones y los alcances que esas dinámicas y declaraciones han tenido a través del tiempo, es posible distinguir cuatro periodos de la trayectoria del patrimonio industrial chileno.

\section{La década de 1970: la emergencia del patrimonio industrial}

$\mathrm{Al}$ igual que en el resto del mundo, durante estos años los criterios de valoración patrimonial en el país comenzaron a alejarse de la idea que asocia lo patrimonial con lo artístico. Sin embargo, el reconocimiento patrimonial de bienes industriales en esta época no significó que la institución encargada del patrimonio en el país, el Consejo 
de Monumentos Nacionales, hubiese incorporado una perspectiva territorial que significara la integración de los conjuntos fabriles distinguidos como patrimonio, tampoco que se relacionara la acción productiva con el paisaje ni que esas activaciones reflejaran la existencia de una valoración social sobre esos restos industriales.

En otras palabras, en un inicio la declaración patrimonial de bienes industriales se centró exclusivamente en el valor histórico que cada elemento poseía en tanto registro material de los procesos económicos y sociales de los cuales fue parte. Pero esto no necesariamente implicaba una mejora en su estado de conservación, puesta en valor, rehabilitación ni menos la posibilidad de una refuncionalización. También resulta interesante identificar durante esta década que en tiempo de los trastornos sociales y políticos ocurridos durante el gobierno de la Unidad Popular (1970-1973), las declaraciones patrimoniales fueran utilizadas políticamente por los propietarios de las viñas Santa Rita y Santa Carolina para evitar que fueran tomadas y expropiadas por sus trabajadores ${ }^{3}$.

\section{La década de 1980: la valoración del ferrocarril}

En el decenio de 1980 se desencadenó una explosiva activación de bienes relacionados con el ferrocarril que encuentra explicación en la importancia que desde mediados del siglo XIX tuvo ese medio de transporte para la conectividad y el desarrollo económico e industrial del país y, consiguientemente, para la consolidación del Estado dentro del territorio nacional. Asimismo, desde que en 1884 se creara la Empresa de Ferrocarriles del Estado, esta prestó un servicio con un fuerte componente social que involucró que el tren se constituyera en un importante dispositivo de construcción de realidades e identidades territoriales, especialmente en las áreas rurales, y que ocupara un lugar fundamental en la memoria de muchos de esos sectores del país.

Ese escenario se transformó en 1979 con la liberalización del transporte público lo que obligó a la Empresa de Ferrocarriles del Estado a autofinanciarse por medio de la enajenación y el traspaso de activos al sector privado y, consecuentemente, el progresivo cierre de los ramales menos rentables de la red ferroviaria nacional, así sus servicios quedaron a distancias cortas e intermedias. Esto significó que durante toda la década de 1980, al prescindir de gran cantidad de material en buenas condiciones de funcionamiento e integridad la empresa dejó de cumplir el rol social que históricamente había desempeñado. Todo esto hizo que trabajadores ferroviarios y muchas de las comunidades a las que el tren había prestado servicios se organizaran espontáneamente en pos del rescate y la conservación del material que se estaba dando de baja, lo que permitió que en 1984 fuera creado el primer museo ferroviario del país, inaugurado en la Quinta Normal de Santiago.

Por último, cabe destacar el rol que en este proceso le cupo a la Asociación Chilena de Conservación del Patrimonio Ferroviario que, creada a comienzos de la década de 1980, desempeñó una destacada labor de sensibilización de las autoridades militares de la época respecto al reconocimiento, la conservación y la puesta en valor de elementos patrimoniales ferroviarios que en ese momento tenían el riesgo de desaparecer ${ }^{4}$.

\section{La década de 1990: la consolidación de lo industrial como patrimonio}

Durante estos años finalizan las declaratorias de bienes relacionados con la minería del salitre que habían comenzado en los años 1970 y atravesado toda la década de 1980. Asimismo, prosigue la patrimonialización de elementos asociados al ferrocarril y se continúan añadiendo, aunque de forma acotada, elementos pertenecientes a otros sectores productivos. Sin embargo, esta década arranca con una importante novedad pues, apenas recuperada la democracia, el Estado emprende distintas líneas de acción en el ámbito cultural: financia a artistas y creadores mediante fondos concursables; impulsa la participación privada en la cultura mediante la Ley 18.985 de donaciones culturales; mejora la legislación cultural existente y genera infraestructura cultural (Muñoz, 2010).

Esto, sumado a que en esos momentos se ejecutaban acciones orientadas a la renovación y el mejoramiento del centro histórico de la ciudad de Santiago, significó que se emprendiera la transformación y la refuncionalización de la antigua estación Mapocho de trenes de esa ciudad como el primer centro cultural del país, proyecto que replicó la tendencia mundial de recuperar y otorgar nuevos usos a espacios industriales abandonados 5 .
3 Comunicación perso nal. Hernán Rodríguez, director del Museo Andino de la viña Santa Rita, 15 de julio de 2015.

4 Información proporcionada por Marco Sandoval, coordinador del Museo Ferroviario de Santiago, entrevistado el 28 de agosto de 2015.

5 Información dada por Ghislaine Asfura, directora de desarrollo de la Corporación Cultural Estación

Mapocho, entrevistada el 23 de septiembre de 2015 . 


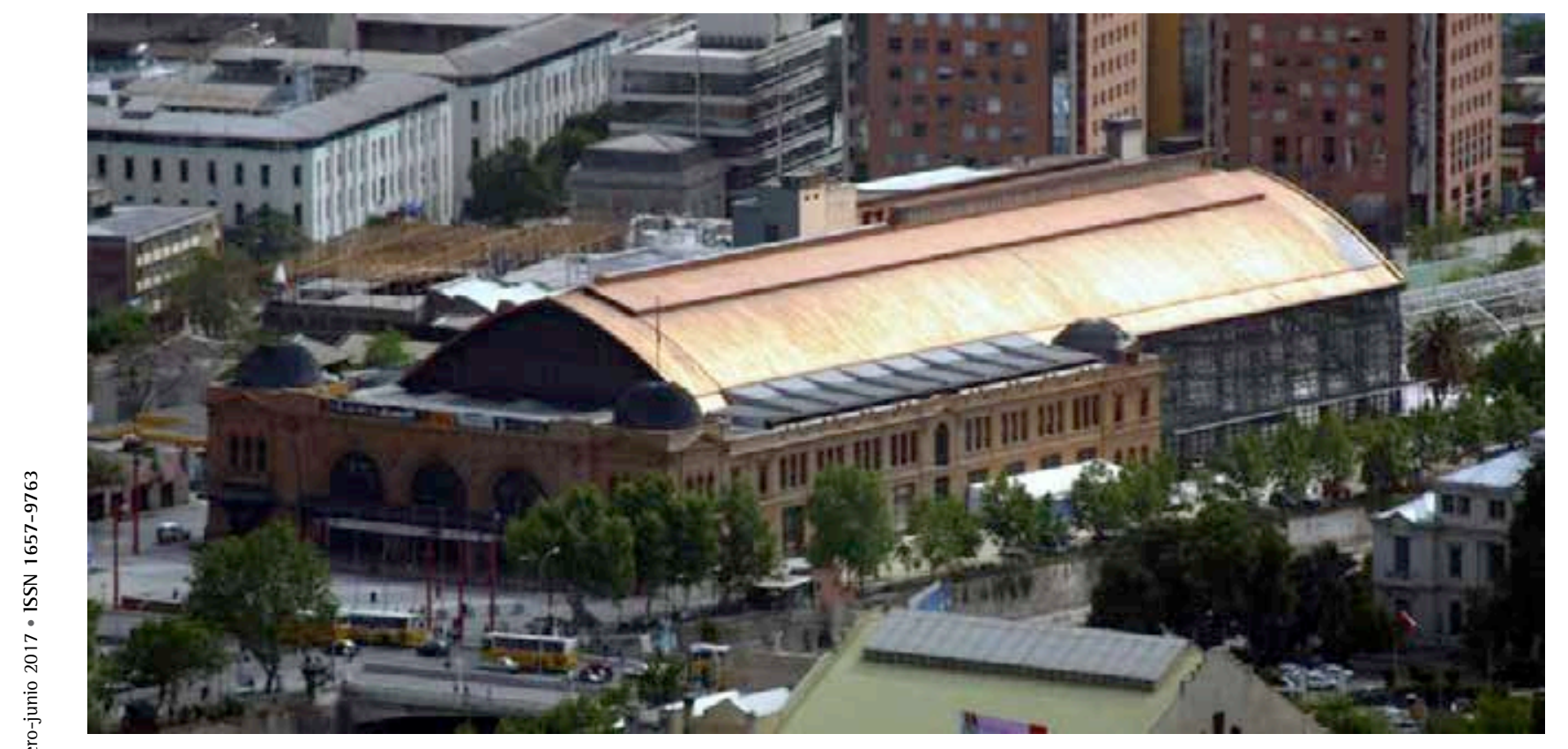

Figura 5: Centro Cultural Estación Mapocho

Fuente:

Gentileza de la Corporación Cultural Estación Mapocho

6 Recuperado de http:// www.estacionmapocho.cl/

7 Por ejemplo, León, 2009; Rojas, Carvajal y Ortega, 2015; Pizzi, Valenzuela y Benavides, 2009; Ortega 2013; entre otros.

8 El company town puede ser entendido como "modelo alternativo a la ciudad tradicional, construidos ex novo con el propósito de conseguir máxima concentración de capital y trabajo mediante la articulación armónica de viviendas, equipamientos y edificios industriales" (Garcés, 2009, p. 144).

9 Chiquicamata se encuentra en pleno desierto de Atacama, a 2.870 msnm, al interior de la Región de Antofagasta y a unos $1.500 \mathrm{~km}$ al norte de la capital, Santiago. La región es la zona minera por excelencia del país.
En efecto, la estación Mapocho fue construida entre 1905 y 1912, en medio del auge económico provocado por el salitre y como parte de las celebraciones del centenario de la independencia del país. Se ubica en el casco histórico de la capital, fue la estación más grande de la red ferroviaria nacional y fue declarada monumento nacional histórico en 1976. No obstante, esa distinción no significó que se revirtiera el avanzado estado de deterioro en el que se encontraba; es más, en 1987 la estación fue clausurada, abandonada y puesta a la venta. Afortunadamente ese negocio no se concretó y el lugar continuó siendo de propiedad estatal para, finalmente, entre los años 1991 y 1994, ser reformada con fondos estatales para albergar el Centro Cultural Estación Mapocho. En 1991 se constituyó la Corporación Cultural de la Estación Mapocho, institución de derecho privado sin fines de lucro que desde entonces se encarga de la preservación, el desarrollo, la administración y la gestión del edificio. Por último, cabe destacar que en 2009 el Centro Cultural Estación Mapocho ganó el V1 Premio Internacional Reina Sofía de Preservación y Conservación del Patrimonio y Difusión de la Cultura ${ }^{6}$.

\section{El siglo XXI: la apropiación social del patrimonio industrial y el rol del sector privado}

La primera década de este siglo destaca porque los elementos que son objeto de declaraciones patrimoniales dejan definitivamente de ser exclusivamente identificados por la institucionalidad competente, el Consejo de Monumentos Nacionales, y también comienzan a ser propuestos por el mundo asociativo, especialistas académicos y diversas instituciones del sector público.

Efectivamente, durante los últimos años ha sido notable el incremento de la sensibilidad social nacional sobre bienes de características patrimoniales, que se ha manifestado por medio de movimientos de defensa, populares y amplios, que por cierto incluyen elementos del ámbito industrial. $\mathrm{Al}$ respecto, destacan las dinámicas de activación patrimonial alrededor del patrimonio ferroviario de las ciudades de Santiago y Valparaíso y que son emprendidas por un sinnúmero de asociaciones y colectivos sociales que, junto a especialistas y otros profesionales, son los artífices de varias páginas web y publicaciones temáticas ${ }^{7}$.

En esta misma línea de acción se sitúan las reivindicaciones patrimoniales en torno a los campamentos pertenecientes a la gran minería cuprífera que fueron erradicados durante los últimos años del siglo XX. Un ejemplo es el antiguo campamento de Chuquicamata, asentamiento urbano industrial fiel representante de los denominados company town ${ }^{8}$. Chuquicamata es la mina a rajo abierto más grande del mundo y sus operaciones industriales comenzaron en $1910^{9}$. En 1992 Chuquicamata fue declarada zona saturada de material particulado respirable y anhídrido sulfúrico, lo que implicó que la empresa propietaria, la Corporación Nacional del Cobre, 
decidiera trasladar a la población del campamento asociado al mineral a la vecina ciudad de Calama. El traslado finalizó en 2004 y tres años después se realizó la ceremonia oficial de cierre del campamento, que alcanzó a cumplir 92 años de vida útil. A partir de entonces numerosos antiguos pobladores se organizaron y, junto con otras instituciones, solicitaron le fuese otorgada al asentamiento la categoría patrimonial. Finalmente, en enero de 2015, el Consejo de Monumentos Nacionales declaró al lugar como monumento nacional en las categorías histórica y zona típica o pintoresca como forma de resguardar los bienes y la identidad asociada al lugar.

Por otra parte, la tendencia a rehabilitar espacios industriales para darles nuevas funciones es un fenómeno en alza en el país, destaca el protagonismo que ha adquirido el sector privado y asociaciones pertenecientes a la sociedad civil en iniciativas orientadas al turismo y el ocio y también a la puesta en marcha de proyectos culturales. Conjuntamente, este tipo de proyectos, además de proteger esos bienes del deterioro, significan la posibilidad de transformarlos en activos para que, mediante su “turistificación”, puedan potencialmente traducirse en beneficios económicos para los lugares en que están insertos (Kanitz, 2000).

Dentro de la primera de estas líneas de acción destaca la transformación del antiguo frigorífico Bories en un lujoso hotel de cinco estrellas. El frigorífico Bories se dedicó entre 1915y 1971 al faenamiento, el procesamiento y la refrigeración de ganado ovino, y se constituyó en un importante polo de desarrollo de la Patagonia ${ }^{10}$. En 1996 el complejo industrial fue declarado monumento nacional histórico y, desde 1999, un grupo de empresarios comenzó el proceso de transformación de esas instalaciones en un exclusivo hotel de lujo. Así, después de más de 10 años de restauraciones y una inversión de 10 millones de dólares, en 2011 fue inaugurado el hotel The Singular ${ }^{11}$.

Una iniciativa similar es la ejecutada en las denominadas ruinas de Huanchaca de la ciudad de Antofagasta ${ }^{12}$. Estas ruinas corresponden a las bases estructurales del establecimiento industrial de Playa Blanca de la Compañía Huanchaca de Bolivia que funcionó entre 1892 y 1902, ese año las instalaciones fueron abandonadas y los terrenos pasaron a propiedad fiscal hasta que en 1964 fueron transferidos gratuitamente a la Universidad Católica del Norte. Diez años después, las ruinas fueron declaradas monumento nacional histórico, pero eso no detuvo su deterioro. En 2006 la empresa Enjoy S. A. ganó la licencia para desarrollar el proyecto Enjoy Antofagasta Casino \&t Resort y al año siguiente nació la Fundación Ruinas de Huanchaca, institución sin fines de lucro compuesta por la Universidad Católica del Norte, Enjoy S. A. y por la Sociedad Química y Minera de Chile que, mediante la Ley 18.985 de donaciones culturales, entregó un importante aporte económico. De esta forma, gracias al apalancamiento de intereses distintos como los universitarios y los empresariales, en 2010 fue creado el Parque Cultural Huanchaca como espacio dedicado al rescate, la protección y la conservación cultural, identitaria y patrimonial de la Región de Antofagasta ${ }^{13}$.

En lo que respecta a la implementación de museos como recursos destinados al aprendizaje y la profundización del conocimiento de la sociedad industrial, es especialmente destacable la rehabilitación de la antigua ballenera de Quintay ${ }^{14}$. Esas instalaciones, que fueron construidas por la Compañía Industrial e inauguradas en 1943, se constituyeron en la ballenera más grande del país y la única que conservó su integridad, operó a plena capacidad hasta su cierre en 1967, cuando fue abandonada. En 1997, producto de un conflicto con un proyecto inmobiliario, fue creada la Fundación Quintay, organización en la que participa un espectro amplio de actores sociales locales y cuyo objetivo es la promoción, el fomento y el desarrollo de la pesca sustentable, la protección, la defensa y la recuperación del medio ambiente marino y el manejo sustentable del borde costero. Al año siguiente, en 1998, le fueron entregados en concesión a la Fundación la mitad de los terrenos de la antigua ballenera con el objetivo de instalar un centro de promoción de respeto al mar y velar por la autenticidad y la integridad de la infraestructura existente por lo que habilitaron en su interior una serie de exhibiciones museográficas. La mitad restante la recibió en concesión la Universidad Andrés Bello, que procedió a la restauración de los antiguos edificios de hormigón armado y albañilería gruesa, de manera que se conservara parte del patrimonio arquitectónico del lugar e inaugurar el Centro de Investigaciones Marinas de Quintay, plataforma de investigación, docencia y desarrollo tecnológico en el área de las ciencias del mar ${ }^{15}$. Finalmente, en 2015 le fue concedida la categoría de monumento nacional histórico a estas antiguas instalaciones balleneras.
$10 \mathrm{El}$ antiguo frigorífico Bories se ubica en Patagonia, en la Región de Magallanes, a pocos kilómetros del Parque Nacional Torres del Paine y a unos $4 \mathrm{~km}$ de la ciudad de Puerto Natales.

11 Recuperado de http:// www.thesingular.com/ patagonia/puertonatales/the-hotel-es.html.

12 La ciudad y puerto de Antofagasta se encuentra en la región del mismo nombre. Es la quinta ciudad con mayor cantidad de habitantes del país y una de las urbes con mayor ingreso per cápita producto de la actividad minera existente en el área.

13 Recuperado de http:// www.ruinasdehuanchaca.cl.

14 Estas antiguas instalaciones balleneras se ubican en la localidad costera de Quintay, a unos $45 \mathrm{~km}$ del puerto de Valparaíso, en la región del mismo nombre, y a 122 $\mathrm{km}$ de Santiago de Chile.

15 Información entregada por René Barrios, presidente del sindicato de pescadores de la caleta de Quintay y tesorero de la Fundación Quintay, entrevistado el 12 de septiembre 2015. 


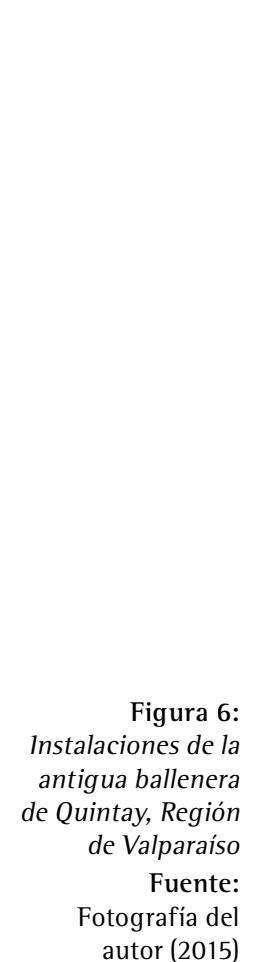

autor (2015)

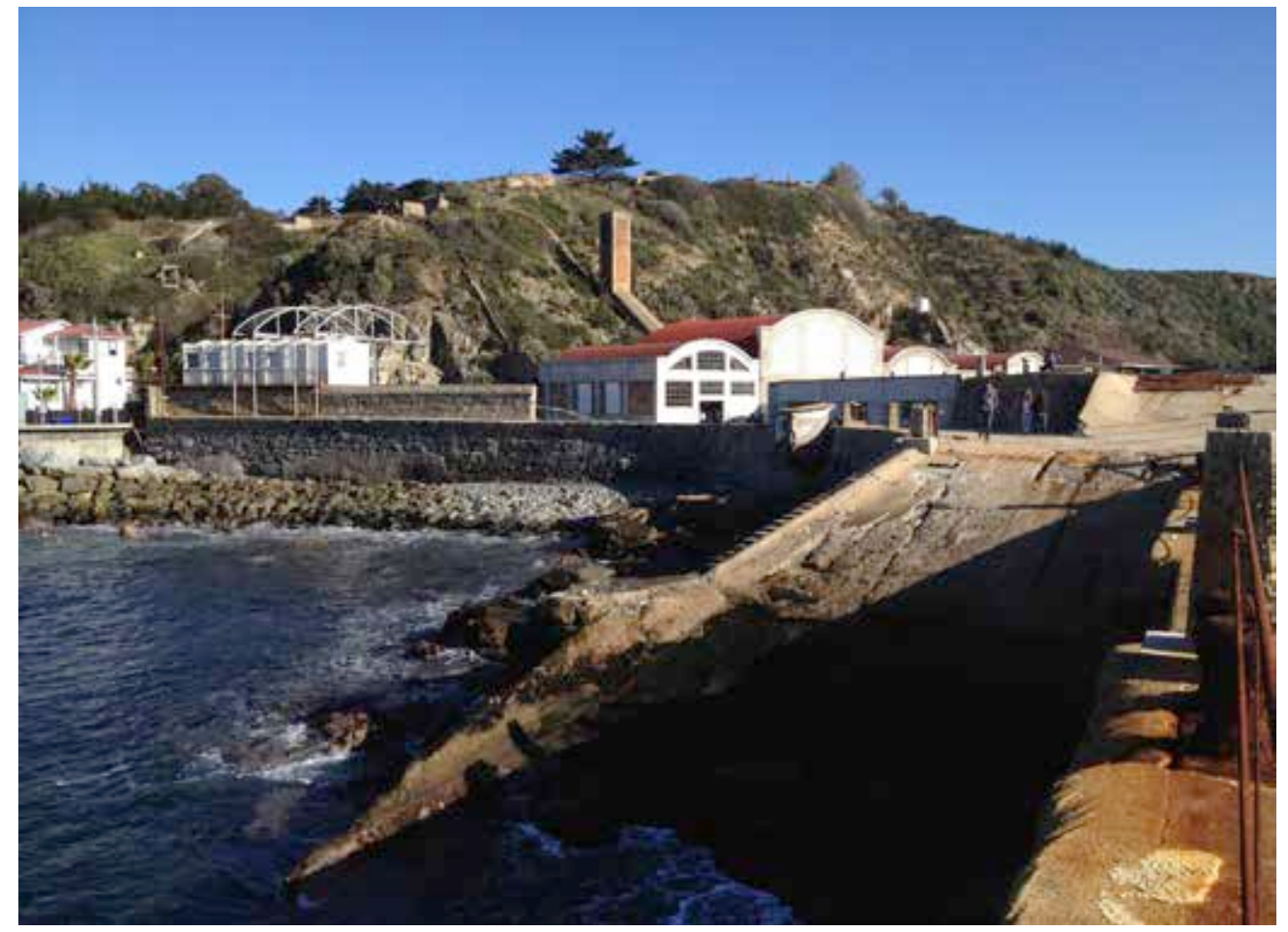

\section{Conclusiones}

Como se aprecia, la valoración social de elementos industriales en Chile demuestra significativos progresos a través del tiempo que le han proporcionado importantes perspectivas y también significativos desafíos. Lo primero queda de manifiesto en el número de proyectos ejecutados por la sociedad civil en torno a elementos o espacios industriales gracias a los fondos de cultura que cada año son convocados por el Consejo de las Artes y la Cultura, la gran cantidad de solicitudes que recibe el Consejo de Monumentos Nacionales por parte de distintas asociaciones y especialistas para declarar bienes industriales como monumentos nacionales y las acciones que diferentes actores sociales ejecutan alrededor de elementos y espacios industriales como es, por ejemplo, la reciente inauguración, en las instalaciones del antiguo aeropuerto de Cerrillos de Santiago de Chile, del Centro Nacional de Arte Contemporáneo ${ }^{16}$.

Sin embargo, este escenario no ha revertido que en Chile el patrimonio sea una prioridad de segundo orden, esté deficientemente valorado, se desenvuelva con recursos insuficientes y que se registre una baja voluntad política respecto a su inclusión en las políticas territoriales. Asimismo, aunque no es despreciable el número de iniciativas destinadas a conocer y conservar bienes industriales con características patrimoniales por parte de asociaciones civiles, la información que estas generan permanece aislada y sin continuidad dado que no es coordinada ni gestionada por ninguna institución de forma centralizada, lo cual impide que la temática avance más sistemáticamente. Esta situación hace extremadamente conveniente considerar la realización de un inventario industrial nacional y una selección de los elementos industriales más destacados y socialmente mejor evaluados de manera de priorizar su estudio, conservación, divulgación y eventual habilitación y reutilización. De hecho, el único trabajo realizado al respecto corresponde al de una tesis doctoral que propone una herramienta de catalogación e inventariado del patrimonio industrial del país (Migone, 2003).

A pesar de esto, las proyecciones del patrimonio industrial nacional pueden estimarse como positivas debido a la importancia que este tipo de elementos está teniendo para los grupos que les dieron vida y que continúan habitando a su alrededor, y los discursos y las acciones que emergen de esa valoración, asimismo de los usos sociales e incluso políticos que actualmente se les adjudica a esos elementos. En tal sentido, es especialmente relevante reparar en el rol que está adquiriendo el patrimonio como mecanismo de reconocimiento y construcción grupal a partir de las experiencias, la memoria y las tradiciones lo-
16 Recuperado de http:// centronacionaldearte.cl/ 
cales, y también como herramienta política y confrontación simbólica. Esto queda en evidencia en el conflicto existente en torno a la antigua fábrica textil Bellavista-Tomé que pone en oposición, por un lado, a la comunidad organizada para impedir que esas instalaciones sean demolidas, y por otro, a un grupo económico que impulsa el cambio del uso de suelos del lugar para ejecutar un proyecto inmobiliario ${ }^{17}$. Este tipo de escenarios da cuenta de la importancia que está teniendo el patrimonio en procesos de defensa y preservación del entorno y la calidad de vida barrial y, asimismo, como una forma de lograr que las poblaciones locales sean consideradas en decisiones que son de su competencia.

En otras palabras, los elementos industriales se han ido convirtiendo en poderosos mecanismos de cohesión social, memoria e identidad de antiguos espacios productivos porque son vistos como "instrumentos de conocimiento, comunicación y valoración de las huellas presentes en un territorio" (Blanco y Río, 2015, p. 235). Es decir, estos bienes se están constituyendo en valiosos activos sociales dada su capacidad para cohesionar y organizar a los individuos en torno a intereses y necesidades comunes.

Algo parecido sucede con los proyectos de intervención, refuncionalización y gestión de antiguos espacios industriales por actores pertenecientes al sector privado. Pues, si bien esas iniciativas en primer lugar obedecen a objetivos de carácter económico, sin duda también representan poner en valor el vínculo existente entre el paisaje, la memoria y las manifestaciones específicas de la industria en un territorio. Pues, aplicar una mirada territorial al conjunto de bienes patrimoniales permite integrarlos y consolidarlos como partes de un espacio en permanente construcción, y los inserta en la trayectoria histórica de cada lugar confiriéndoles estatus explicativo (García, Meer y De la Puente, 2012).

Vale decir, entender el patrimonio a escala territorial implica construir e interpretar los espacios mediante la activación de parte de las manifestaciones culturales que existen en su interior, también se deben considerar los esquemas cognitivos y simbólicos con que los grupos se relacionan con su territorio (Torrico y Hernández, 2012). De esa forma, el patrimonio emerge como un recurso que, más allá del ámbito simbólico, progresivamente comienza a adquirir protagonismo en las dinámicas de construcción y ordenación territorial y/o dentro de procesos de desarrollo local asociados al turismo y el ocio.

\section{Referencias}

Aguilar, 1. (2007). Arquitectura industrial, testimonio de la era de la industrialización. Bienes culturales, Revista del Instituto del Patrimonio Histórico Español, 7, 71-101.

Alonso, R. (2002). Aspectos normativos del patrimonio industrial. La ley del principado de Asturias 1/2001, de 6 de marzo de patrimonio cultural. En Álvarez, M. Á. (coord.). Patrimonio Industrial: lugares de la memoria. Proyectos de reutilización en industrias culturales, turismo y museos. Gijón: CiccesIncuna, p. 109-128.

Álvarez, M. Á. (2010). Patrimonio industrial, paisaje y desarrollo territorial. Áreas, Revista Internacional de Ciencias Sociales, 29, 21-29.

Benito del Pozo, P. (2002). Patrimonio industrial y cultura del territorio. Boletín de la Asociación de Geógrafos Españoles, 34, 213-227.

Benito del Pozo, P. (2012). Territorio, paisaje y herencia industrial: debates y acciones en el contexto europeo. Documents d'Anàlisi Geogràfica, 58(3), 443-457.

Bergeron, L. y Dorel-Ferre, G. (1996). Le patrimoine industriel. Un nouveau territoire. Paris: Éditions Liris.

Bergeron, L. (2002). El patrimonio industrial, ¿qué hacer? En Álvarez, M. Á. (coord.). Patrimonio industrial: lugares de la memoria. Proyectos de reutilización en industrias culturales, turismo y museos. Gijón: Cicees-Incuna, p. 11-16.

Blanco, S. y Río, A. (2015). La fábrica como escenografía: La puesta en escena del patrimonio industrial. En Álvarez, M. Á. (ed.). Espacios industriales abandonados. Gestión del patrimonio y medio ambiente. Gijón: Cicees, p. 229-235.

Cañizares, M. del C. (2005). Territorio y patrimonio minero-industrial en Castilla-La Mancha. Cuenca: Ediciones de la Universidad de Castilla-La Mancha.

Casanelles, E. (2007). Nuevo concepto de Patrimonio Industrial, evolución de su valoración, significado y rentabilidad en el contexto internacional. Bienes culturales, Revista del Instituto del Patrimonio Histórico Español, 7, 59-70.
17 La fábrica de paños Bellavista-Tomé se ubica en la comuna de Tomé, en la Región del Biobío. La comuna forma parte del área metropolitana del Gran Concepción que, junto a la del Gran Valparaíso, es la segunda con mayor población del país después de Santiago. Las instalaciones de la fábrica textil fueron construidas en 1865 $y$ adquirieron un destacado rol en la conformación del paisaje urbano, la historia y la identidad del lugar. En 2007 la fábrica cerró y su propiedad pasó a manos del grupo económico Sabat para ser demolida y construir un proyecto inmobiliario en su lugar. Para evitarlo, la población local se organizó en torno a la Mesa Ciudadana por el Patrimonio de Tomé y solicitó al Consejo de Monumentos Nacionales que se le diera al inmueble la categoría de monumento histórico. El 13 de abril de 2016 la antigua fábrica fue declarada patrimonio por esa institución pero, a pesar de esto, el conflicto se mantiene debido a que las instalaciones son de propiedad privada. 
Cerdà, M. (2008). Arqueología industrial. Teoría y práctica. Valencia: Universitat de València.

Comité Internacional para la Conservación del Patrimonio Industrial (2003). Carta de Nizhny Tagil sobre el patrimonio industrial. Moscú.

Consejo de Europa (1987). Quelle politique pour le patrimoine industriel? Rapport du Colloque de Lyon, Vaulx-en-Velin, 22-25 octobre 1985. Strasbourg.

Cormín, F. (2005). La segunda industrialización en el marco de la primera globalización (18701913). En Cormín F.; Hernández, M. y Llopis, E. (eds.). Historia económica mundial: siglos $X-X X$. Madrid: Editorial Crítica, p. 239-286.

Dambron, P. (2004). Patrimoine industriel et développement local. Paris: Editions Jean Delaville.

Davallon, J. (2006). Le don du patrimoine: Une approche communicationnelle de la patrimonialisation. Paris: Hermès Sciences-Lavoisier.

Feria, J. M. (2010). Patrimonio territorial y desarrollo sostenible: un estudio comparativo en lberoamérica y España. Estudios Geográficos, LXXI(268), 129-159.

Fernández-Baca, R. (2007). Reflexiones sobre el patrimonio industrial. Bienes culturales, Revista del Instituto del Patrimonio Histórico Español, 7, 53-57.

François, H.; Hirczak, M. y Senil, N. (2006). Territoire et patrimoine: La co-construction d'une dynamique et de ses ressources. Revue d'économie régionale et urbaine, 5, 683-700.

Garcés, E. (2009). Potrerillos, Paipote y El Salvador, ciudades del cobre en Atacama. En Empresa Nacional de Minería (ed.). Chile minero. ENAMI en la historia de la pequeña y mediana minería chilena. Santiago de Chile: Ocho Libros Editores, p. 143-159.

García, J. C.; de Meer, Á. y de la Puente, L. (2012). Experiencias de análisis territorial y zonificación para la integración del desarrollo, el patrimonio y el paisaje en la ordenación del territorio. Ciudades, 15(1), 89-113.

Homobono, J. 1. (2006-2007). El patrimonio industrial y sus activaciones: Turismo, museos, ecomuseos y reutilización. Revista Kobie, 12, 5-33.

Instituto del Patrimonio Cultural de España (2011). Plan Nacional de Patrimonio Industrial. Madrid: Ministerio de Educación, Cultura y Deporte.
Kanitz, S. (enero 19, 2000). Turistificando o Brasil. Revista Veja [En línea] edición 1632, 33(3), 20. Recuperado de http://veja.abril.com.br/ acervodigital/home.aspx.

Kirshenblatt-Gimblett, B. (2001). La cultura de les destinacions: Teoritzar el patrimoni. Revista d'Etnologia de Catalunya, 9, 44-61.

León, S. (2009). Valparaíso sobre rieles. El ferrocarril, los tranvías y los 30 ascensores. Valparaíso: Editorial Puerto de Escape.

Lopes, J. M. (2001). Museología y museografía industrial. En Álvarez, M. Á. (coord.). Arqueología industrial, patrimonio y turismo cultural. Gijón: Cicees-Incuna, p. 41-52.

Llurdés, J. C. (1999). Patrimonio industrial y patrimonio de la humanidad. El ejemplo de las colonias textiles catalanas: Potencialidades turísticas y algunas reflexiones. Boletín de la Asociación de Geógrafos Españoles, 28, 147-160.

Marrodán, E. (2007). De la fascinación a la nostalgia. La ruina industrial en el paisaje contemporáneo. Bienes culturales, Revista del Instituto del Patrimonio Histórico Español, 7, 103-117.

Mata, R. (2008). El paisaje, patrimonio y recurso para el desarrollo territorial sostenible. Conocimiento y acción pública. Arbor, revista de ciencia, pensamiento y cultura, 184(729), 155-172.

Migone, J. (2003). Preinventario para la catalogación del patrimonio industrial chileno. Santiago de Chile: Universidad Central de Chile.

Muñoz, N. (2010). Democracia e institucionalidad cultural en Chile: las políticas públicas como espacio de mediación. Ponencia presentada en el Quinto Congreso Latinoamericano de Ciencia Política. Buenos Aires, 28 al 30 julio de 2010.

Ortega, A. (2013). Entre rieles. Patrimonio ferroviario y configuración del paisaje cultural urbano del Ferrocarril al Sur entre Estación Central y San Bernardo (1905-2013). Tesis presentada para optar al grado de Magíster en Desarrollo Urbano. Santiago de Chile: Universidad Católica de Chile.

Pardo, C. (2006). Territorios de la industria, turismo industrial y desarrollo territorial. En Lacosta, A. (coord.). Turismo y cambio territorial: ¿eclosión, aceleración, desbordamiento? Zaragoza: Prensas Universitarias de Zaragoza, p. 243-253. 
Pardo, C. (2008). Turismo y patrimonio industrial: Un análisis desde la perspectiva territorial. Madrid: Editorial Síntesis.

Pardo, C. (2011). Paisajes industriales e industrias para el turismo: simbolismo patrimonial y alcance territorial. Rotur, revista de ocio y turismo, 4, 15-32.

Pérez, L. y Parra, C. (2004). Paisajes culturales: el parque patrimonial como instrumento de revalorización y revitalización del territorio. Teoria, 13, 9-24.

Pizzi, M.; Valenzuela, M. P.y Benavides, J. (2009). El patrimonio arquitectónico industrial en torno al ex ferrocarril de circunvalación de Santiago: Testimonio del desarrollo industrial manufacturero en el siglo XX. Santiago de Chile: Editorial Universitaria.

Prats, L. (1997). Antropología y patrimonio. Barcelona: Editorial Ariel.

Quivik, F. L. (2000). Landscapes as Industrial Artefacts: Lessons from Environmental History. The Journal of the Society for Industrial Archaeology, 26, 55-64.

Rojas, L.; Carvajal, M. de los Á. y Ortega, A. (2015). Entre rieles y chimeneas. Un recorrido por el barrio obrero y ferroviario San Eugenio. Santiago de Chile: Colectivo Rescata.

Sabaté, J. y Benito del Pozo, P. (2010). Paisajes culturales y proyecto territorial: un balance de treinta años de experiencia. ldentidades: territorio, cultura, patrimonio, 2, 2-21.

Tajter, M. (agosto 1, 2008). El patrimonio industrial de Barcelona entre la destrucción y la conservación, 1999-2008. Scripta Nova, revista electrónica de geografía y ciencias sociales [en línea], XII(270) (140). Recuperado de http://www.ub.edu/geocrit/sn/sn-270/ sn-270-140.htm.

Therrien, M. (2008). Patrimonio y arqueología industrial: ¿investigación vs. protección? Políticas del patrimonio industrial en Colombia. Apuntes, 21(1), 44-61.

Torrico, J. y Hernández, E. (2012). Paisaje e identidad territorial. Aproximación desde el caso de una provincia andaluza. XVII Congreso de Estudios Vascos: Innovación para el progreso social sostenible. Eusko lkastuntza, Donostia, p. 473-486. 